\title{
Broad-spectrum antibacterial activity by a novel abiogenic peptide mimic
}

Correspondence
Klaus Nüsslein
nusslein@microbio.umass.edu

Received 23 December 2005

Revised 23 March 2006

Accepted 29 March 2006

\author{
Klaus Nüsslein, ${ }^{1}$ Lachelle Arnt, ${ }^{2} \dagger$ Jason Rennie, ${ }^{1}$ Cullen Owens ${ }^{1} \ddagger$ \\ and Gregory N. Tew ${ }^{2}$
} Department of Microbiology ${ }^{1}$ and Polymer Science and Engineering Department ${ }^{2}$, University of
Massachusetts, Amherst, MA 01003, USA

\begin{abstract}
The human-mediated use and abuse of classical antibiotics has created a strong selective pressure for the rapid evolution of antibiotic resistance. As resistance levels rise, and the efficacy of classical antibiotics wanes, the intensity of the search for alternative antimicrobials has increased. One class of molecules that has attracted much attention is the antimicrobial peptides (AMPs). They exhibit broad-spectrum activity, they are potent and they are widespread as part of the innate defence system of both vertebrates and invertebrates. However, peptides are complex molecules that suffer from proteolytic degradation. The ability to capture the essential properties of antimicrobial peptides in simple easy-to-prepare molecules that are abiotic in origin and non-proteolytic offers many advantages. Mechanistic and structural knowledge of existing AMPs was used to design a novel compound that mimics the biochemical activity of an AMP. This report describes the development and in vitro characterization of a small peptide mimic that exhibited quick-acting and selective antibacterial activity against a broad range of bacteria, including numerous clinically relevant strains, at low MIC values.
\end{abstract}

\section{INTRODUCTION}

Bacterial drug resistance is emerging as one of the most significant challenges to human health (Walsh, 2003). Efforts to discover and develop new antibiotics have intensified. Antimicrobial peptides (AMPs), a ubiquitous group of natural compounds, have attracted considerable attention due to their broad-spectrum killing activity and novel modes of action (Tamayo et al., 2004; Bucki et al., 2004; Zasloff, 2002; Strøm et al., 2003). AMPs appear to play a role in maintaining microbial diversity in a broad range of habitats. These potent toxins ward off invading microbes and allow the producing strains to secure limiting resources. It has been shown that AMPs also play a major role in the action of the innate host defence mechanisms against infections (Hancock \& Diamond, 2000).

tPresent Address: Clorox Services Company, PO Box 493, Pleasanton, CA 94566, USA.

‡Present Address: Department of Neurology, Beth Israel Deaconess Medical Center, Boston, MA 02215, USA.

Abbreviations: AMP, antimicrobial peptide; FA, facially amphiphilic; $\mathrm{HC}_{50}$, dose required to lyse $50 \%$ of RBCs; MBC, minimal bactericidal concentration; mPE, meta-phenylene ethynylene; RBC, red blood cell.

A table showing the results of in vitro tests of antimicrobial activities against a group of selected bacterial species of the peptide mimic mPE after 6 and $20 \mathrm{~h}$, and its selectivity index, is available as supplementary data with the online version of this paper (at http://mic.sgmjournals.org).
Despite the structural diversity of AMPs, which include over 700 known peptides produced by organisms ranging from microbial eukaryotes to bacteria (Zasloff, 2002; Andreu \& Rivas, 1998; Broekaert et al., 1997; Bulet et al., 1999), most seem to act as membrane-disturbing agents that are receptor-independent, although other mechanisms continue to be discussed (Tamayo et al., 2004; Toke, 2005; Huang, 2000; Shai \& Oren, 2001; Zhang et al., 2001). In addition to this conserved mode of action, many of these peptides adopt amphiphilic conformations in which cationic and non-polar groups segregate to opposite sides of the $3 \mathrm{D}$ structure, as illustrated for the well studied magainin analogue, which was isolated from the skin of the African clawed frog Xenopus laevis and is shown in Fig. 1 (Guerrero et al., 2004). The resulting structure is referred to as facially amphiphilic (FA), since two discrete surfaces, or faces, of the overall structure appear to be critical to its function.

Antimicrobial peptides provide a rich resource for the development of novel antibiotic compounds (Porter et al., 2000; Li et al., 1999; Kohli et al., 2002; Yount \& Yeaman, 2005). However, peptide drugs are rather large complex molecules and thus pose challenges in terms of stability and delivery. For example, the small AMP magainin (23 aa) has a molecular mass of $2467 \mathrm{Da}$. The ability to capture the biological activity of AMPs in much smaller and simpler molecules is important for both fundamental and practical reasons (Liu et al., 2004; Toke, 2005), as it will provide insight into the essential design elements needed to mimic 


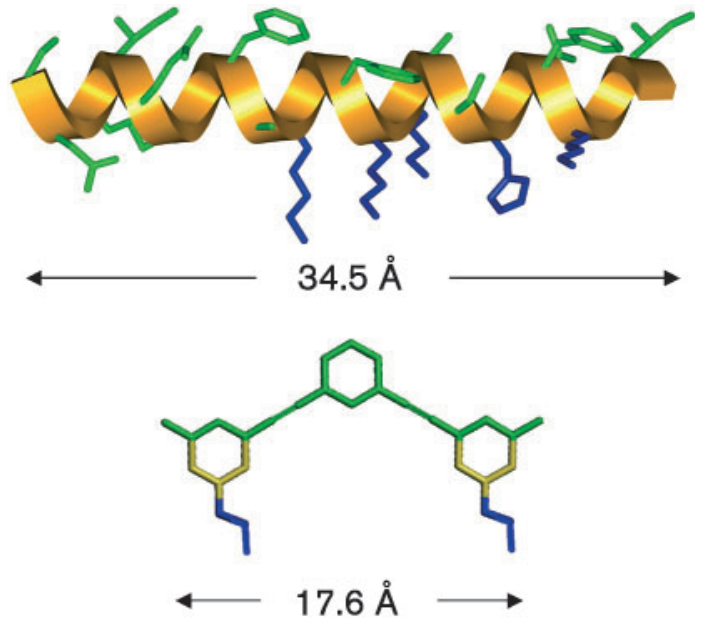

Fig. 1. Structures of the well studied natural AMP magainin-II (top) and the peptide mimic mPE (bottom). The mimic is achiral and non-peptidic, and has an extended mPE backbone that carries a broad hydrophobic upper part (green), while the opposite polar side is FA and cationic (blue). Beyond the FA structure, the mPE molecule is only half as long as the magainin.

biological activity and might enable the development of novel antibiotics (Tew et al., 2002; Arnt et al., 2004). In the present study, we developed and tested an abiotic analogue of biotic AMPs, resulting in an FA, non-chiral and lowmolecular-mass molecule.

\section{METHODS}

Bacterial strains and growth medium. If not otherwise indicated, the origin of the bacterial strains used in this study was clinical isolation or a stock culture collection at the Department of Microbiology, University of Massachusetts, purchased from the ATCC (Table 1). The strains included pathogens, commensals, slow- and fast-growing strains, as well as capsule and non-capsule formers. All bacterial cells were stored in $20 \%(\mathrm{v} / \mathrm{v})$ glycerol at $-80^{\circ} \mathrm{C}$ prior to their use. Cells were grown aerobically, with agitation, in liquid Mueller-Hinton medium (Difco) at $37^{\circ} \mathrm{C}$. The purity of cultures was tested by serial transfer on agar-solidified Mueller-Hinton medium and confirmed by light microscopy.

Microbicidal assays. All in vitro susceptibility testing was done with bacterial cultures grown in Mueller-Hinton medium to midexponential phase, using standard protocols for the broth microdilution technique (National Committee for Clinical Laboratory Standards, 2003). The antimicrobial cationic peptide polymyxin B (Sigma) served as a control. The FA test compound meta-phenylene ethynylene ( $\mathrm{mPE}$ ) does not readily dissolve in aqueous solution, and thus it was dissolved in DMSO prior to its addition to bacterial suspensions. Aliquots of this stock solution were distributed in five steps of a twofold dilution series, in the flat-bottom wells of a 96-well tissue-culture plate set up for MIC determinations (Costar; Corning). Here, MIC refers to the lowest concentration of antimicrobial compound in which growth of a given strain is reduced by $50 \%\left(\mathrm{MIC}_{50}\right)$ or $90 \%\left(\mathrm{MIC}_{90}\right)$ over a period of $6 \mathrm{~h}$. To facilitate comparisons, and to be consistent with other reports, we also measured $20 \mathrm{~h}$ MIC values (see supplementary Table S1, available at http://mic.sgmjournals.org). All MIC values reported are based on three or four experimental repeats. The concentrations employed for control experiments with polymyxin B were obtained from the literature. Comparison with initial MIC values obtained in glass tubes confirmed that there was no significant reduction of available mPE due to adsorption to the plastic subsequently used for the 96-well plates. Additional MIC experiments were performed to evaluate the potential antimicrobial effect of DMSO in the absence of mPE. Bacteriostatic activity in the presence of DMSO was not detected for any of the strains tested (data not shown).

Minimal bactericidal concentrations (MBCs) were measured by preparing serial ten- and twofold dilutions from the MIC assay and plating the dilutions on nutrient agar plates. The MBC is defined as the minimum concentration at which there was a $99.9 \%$ reduction in the number of c.f.u. (Barry, 1976).

Haemolysis assay. Haemolytic activity was determined by using an erythrocyte haemolysis assay, which involved incubating a $0.35 \%$ $(\mathrm{v} / \mathrm{v})$ suspension of fresh human red blood cells (RBCs; collected with $1.8 \mathrm{mg} \mathrm{K} \mathrm{K}_{2}$ EDTA $\mathrm{ml}^{-1}$ ) in $10 \mathrm{mM}$ Tris buffer containing $150 \mathrm{mM} \mathrm{NaCl}$, at $\mathrm{pH} 7 \cdot 0$, with varying amounts of mPE. RBCs were obtained from healthy donors aged 25-40 years who had not been exposed to antimicrobial treatment for at least 5 months prior to the blood donation. Haemolysis experiments were prepared by combining $80 \mu \mathrm{l}$ washed RBCs with a $20 \mu \mathrm{l}$ volume of buffer and $\mathrm{mPE}$ in sterile flat-bottom 96-well plates for $30 \mathrm{~min}$ at $37^{\circ} \mathrm{C}$. Following incubation, the suspensions were sedimented by centrifugation and release of haemoglobin was monitored by absorbance of the diluted supernatant at $414 \mathrm{~nm}$. The control for $100 \%$ haemolysis was the addition of Triton X-100 $(1 \%, \mathrm{v} / \mathrm{v})$ to the suspended RBCs, while a suspension of RBCs in saline buffer functioned as the zero-haemolysis control. A non-linear exponential curve-fitting plot of $A_{414}$ versus the concentration of added $\mathrm{mPE}$ was used to calculate the $\mathrm{HC}_{50}$, which is the dose required to lyse $50 \%$ of the RBCs.

Antibacterial activity in the presence of blood. The antibacterial activity of $\mathrm{mPE}$ in the presence of whole blood was examined in sterile 96-well plates in a series of three experiments: (a) co-incubation of blood, $\mathrm{mPE}$ and a suspension of bacteria for $30 \mathrm{~min}$ at $37^{\circ} \mathrm{C}$; (b) a mixture of blood and $\mathrm{mPE}$ pre-incubated for $30 \mathrm{~min}$ at $37^{\circ} \mathrm{C}$, after which the suspension of bacteria was added; (c) blood was mixed with the suspension of bacteria and pre-incubated for $30 \mathrm{~min}$ at $37^{\circ} \mathrm{C}$, after which $\mathrm{mPE}$ was added. At the end of each $30 \mathrm{~min}$ pre-incubation, aliquots were diluted twofold in 96-well plates and incubated at $37^{\circ} \mathrm{C}$ for $6 \mathrm{~h}$. Growth inhibition was determined by plating out dilutions from each well. The bacterial strains used were Escherichia coli D31 and Bacillus subtilis ATCC 8037. The reported results are means from duplicate experiments, with standard deviations of $\pm 5 \cdot 8 \%$ for E. coli and $\pm 8 \cdot 8 \%$ for B. subtilis.

Bactericidal kinetics. Time-kill studies were performed for the Gram-negative E. coli D31 and the Gram-positive B. subtilis ATCC 8037, to measure the time dependence of bactericidal activity by mPE; the methods followed the guidelines of the NCCLS (National Committee for Clinical Laboratory Standards, 1999), with minor variations. Cells grown in Mueller-Hinton broth to an $\mathrm{OD}_{600}$ of $\sim 0.2$ in mid-exponential phase were adjusted to an $\mathrm{OD}_{600}$ of 0.02 and treated with a range of $\mathrm{mPE}$ concentrations from 0 to 2 times the $\mathrm{MIC}_{90}$ for each strain. Aliquots from the assay were removed at certain time intervals $(0,3,5,10,15$ and $30 \mathrm{~min})$, immediately diluted 1:100 to remove the effects of the drug, and triplicates of serial tenfold dilutions were spread plated on Mueller-Hinton agar for viable cell counts. After $18 \mathrm{~h}$ incubation at $37^{\circ} \mathrm{C}$, data were recorded as survival rates (c.f.u.), based on $100 \%$ survival for the untreated control. Based on the reported activity of biogenic FA host-defence proteins, the killing of $99.9 \%$ of the inoculum in less than 60 min was our target (Steinberg et al., 1997). 
Table 1. In vitro testing of antibacterial activity, and selectivity index, of $\mathrm{mPE}$

MIC values for strains incubated with $\mathrm{mPE}$ for $6 \mathrm{~h}$ are given in $\mu \mathrm{g} \mathrm{ml}^{-1}$. In vitro testing of the antimicrobial activity of selected strains over time is shown in supplementary Table S1 (available at http:// mic.sgmjournals.org).

\begin{tabular}{|c|c|c|c|}
\hline Strain & $\mathrm{MIC}_{50}$ & $\mathrm{MIC}_{90}$ & $\mathrm{HC}_{50} / \mathrm{MIC}_{50}$ * \\
\hline \multicolumn{4}{|l|}{ Gram-negative } \\
\hline Enterobacter cloacae ATCC 13047 & $1 \cdot 7$ & $3 \cdot 4$ & 45 \\
\hline Escherichia coli D31†॥ & $0 \cdot 8$ & $1 \cdot 5$ & 89 \\
\hline Escherichia coli $\mathrm{C} 1 \mathrm{~S} \ddagger$ & $0 \cdot 4$ & $0 \cdot 8$ & 179 \\
\hline Klebsiella aerogenes ATCC 35150 & $2 \cdot 0$ & $3 \cdot 4$ & 38 \\
\hline Klebsiella pneumoniae ATCC 13883॥ & $0 \cdot 9$ & $1 \cdot 6$ & 83 \\
\hline Moraxella catarrhalis ATCC 25240 & $0 \cdot 4$ & $0 \cdot 8$ & 179 \\
\hline Neisseria sicca ATCC 29256 & $1 \cdot 7$ & $3 \cdot 4$ & 45 \\
\hline Proteus vulgaris ATCC 13315 & $1 \cdot 7$ & $3 \cdot 4$ & 45 \\
\hline Pseudomonas aeruginosa ATCC 10145॥ & $1 \cdot 7$ & $3 \cdot 4$ & 45 \\
\hline Salmonella typhimurium ATCC 29631 & $2 \cdot 4$ & $3 \cdot 4$ & 31 \\
\hline Serratia marcescens ATCC 43861 & $2 \cdot 4$ & $3 \cdot 4$ & 31 \\
\hline Francisella tularensis ATCC $17135 \$$ & $<1 \cdot 0$ & $1 \cdot 0$ & $>75$ \\
\hline \multicolumn{4}{|l|}{ Gram-positive } \\
\hline Bacillus anthracis ATCC $1099 \$$ & $0 \cdot 8$ & $1 \cdot 0$ & 94 \\
\hline Bacillus cereus var. mycoides & $0 \cdot 4$ & $1 \cdot 7$ & 179 \\
\hline Bacillus atrophaeus ATCC 9372 & $1 \cdot 7$ & $3 \cdot 4$ & 45 \\
\hline Bacillus subtilis ATCC 8037II & $0 \cdot 6$ & $1 \cdot 6$ & 125 \\
\hline Enterococcus faecalis ATCC 19433 & $0 \cdot 4$ & $0 \cdot 8$ & 179 \\
\hline Listeria monocytogenes ATCC 35152 & $0 \cdot 8$ & $1 \cdot 7$ & 89 \\
\hline Staphylococcus aureus ATCC 25923II & $0 \cdot 4$ & $1 \cdot 3$ & 188 \\
\hline Staphylococcus epidermidis ATCC 155 & $0 \cdot 4$ & $0 \cdot 8$ & 179 \\
\hline Staphylococcus saprophyticus ATCC 15305 & $0 \cdot 4$ & $0 \cdot 8$ & 179 \\
\hline Streptococcus agalactiae ATCC 13813 & $0 \cdot 4$ & $0 \cdot 8$ & 179 \\
\hline Streptococcus gordonii ATCC 33399 & $1 \cdot 7$ & $3 \cdot 4$ & 45 \\
\hline
\end{tabular}

*Selectivity index. The $\mathrm{HC}_{50}$ of $\mathrm{mPE}$ was determined as $75 \mu \mathrm{g} \mathrm{ml}^{-1}$ by extrapolating a best-fit curve to $50 \%$ cell lysis.

$\dagger$ Clinical isolate, University of Pennsylvania (Monner et al., 1971).

$\ddagger$ Clinical isolate, uropathogenic strain, University of Massachusetts culture collection.

$\S$ Tests for strains of $F$. tularensis and B. anthracis were performed by a licensed contract laboratory.

IISelected strains were tested against polymyxin B as a control, and these included: E. coli D31 (MIC ${ }_{50}$ $0 \cdot 5 \mu \mathrm{g} \mathrm{ml}^{-1}$ ), K. pneumoniae ATCC $13883\left(\mathrm{MIC}_{50} 0 \cdot 5 \mu \mathrm{g} \mathrm{ml}^{-1}\right.$ ), Pse. aeruginosa ATCC 10145 (MIC $_{50}$ $0 \cdot 4 \mu \mathrm{g} \mathrm{ml}^{-1}$ ), B. subtilis ATCC $8037\left(\mathrm{MIC}_{50} 0 \cdot 4 \mu \mathrm{g} \mathrm{ml}^{-1}\right.$ ), and Sta. aureus ATCC $25923\left(\mathrm{MIC}_{50} 13 \cdot 3 \mu \mathrm{g}\right.$ $\mathrm{ml}^{-1}$ ). Magainin II was tested against E. coli D31 ( $\mathrm{MIC}_{50} 12 \mu \mathrm{g} \mathrm{ml}^{-1}$ ) previously (Tew et al., 2002), and is included for comparison.

Cytoplasmic membrane permeabilization. Cytoplasmic membrane permeability was determined using the membrane-potentialsensitive cyanine dye diSC3-5. This dye is known to distribute between bacterial cells and the surrounding medium, depending on the membrane potential gradient. Once inside the membrane, the dye aggregates and self-quenches. With the addition of a membranepermeabilizing agent, the dye is released and the increase of fluorescence can be monitored over time. In this experiment, Staphylococcus aureus ATCC 25923, in mid-exponential phase, was collected by centrifugation, washed once with buffer ( 5 mM HEPES, $\mathrm{pH} 7 \cdot 2,5 \mathrm{mM}$ glucose) and resuspended to an $\mathrm{OD}_{600}$ of $0 \cdot 05$. The cells were incubated with $0 \cdot 4 \mu \mathrm{M}$ diSC3-5 for $1 \mathrm{~h}$, for maximal uptake of the dye, after which $100 \mathrm{mM} \mathrm{KCl}$ was added to equilibrate the cytoplasmic and external potassium ion concentrations. The cells were mixed with the desired concentration of $\mathrm{mPE}$ and the fluorescence was monitored at an excitation wavelength of $622 \mathrm{~nm}$ and an emission wavelength of $670 \mathrm{~nm}$. Dye released with the addition of $1 \%$ DMSO was monitored as a control and showed no increase in fluorescence intensity due to leakage over the entire course of the experiment.

Synthesis and characterization of mPE. mPE was synthesized using a technique similar to that reported previously for an $\mathrm{mPE}$ molecule with different stoichiometry (Arnt et al., 2004; Arnt \& Tew, 2002). The dibromoethyl amine monomer was coupled with diethynylbenzene using Sonogoshira coupling in a $4: 1$ stoichiometry. The compound was then purified to homogeneity by silica gel chromatography, to yield a white solid (yield $30 \%$ ). ${ }^{1} \mathrm{H}-\mathrm{NMR}$ $\left(\mathrm{CDCl}_{3}\right): \delta=7 \cdot 68(\mathrm{t}, 1 \mathrm{H}$, phenyl $\mathrm{H}), 7 \cdot 56(\mathrm{t}, 2 \mathrm{H}$, phenyl $\mathrm{H}), 7 \cdot 51$ (t, $1 \mathrm{H}$, phenyl $\mathrm{H}), 7 \cdot 48(\mathrm{~d}, 1 \mathrm{H}$, phenyl $\mathrm{H}), 7 \cdot 37(\mathrm{~d}, 1 \mathrm{H}$, phenyl $\mathrm{H})$, $7 \cdot 34(\mathrm{~m}, 2 \mathrm{H}$, phenyl $\mathrm{H}), 7 \cdot 31(\mathrm{~m}, 2 \mathrm{H}$, phenyl $\mathrm{H}), 4 \cdot 58(\mathrm{~s}, 2 \mathrm{H}$, 
$2 \mathrm{NH}), 3 \cdot 38\left(\mathrm{~m}, 4 \mathrm{H}, 2 \mathrm{CH}_{2}\right), 2 \cdot 79\left(\mathrm{t}, 4 \mathrm{H}, 2 \mathrm{CH}_{2}\right)$ and $1 \cdot 46(\mathrm{~s}, 18 \mathrm{H}$, $\left.6 \mathrm{CH}_{3}\right)$ p.p.m. The synthesis and commercial use of mPE are protected by US Provisional Patent WO-02/072007-A2.

\section{RESULTS AND DISCUSSION}

We set out to develop a small molecule that was an FA, low-molecular-mass, abiogenic analogue of the biotic AMP magainin. Fig. 1 shows a representation of our most active compound, which was discovered from structure-activity studies of more than $25 \mathrm{mPE}$ derivatives. The resulting compound, termed mPE, has a molecular mass of $522 \mathrm{Da}$, is non-chiral and contains no proteolytic bonds. It was found to be a fast-acting broad-spectrum toxin, active against more than 23 bacterial strains. In the presence of human RBCs, mPE selectively targeted bacterial membranes for several bacterial species and it rapidly disrupted phospholipid membranes of the target cells.

A series of biological tests confirmed that mPE recapitulated the essential biochemical characteristics of AMPs. It showed selective microbicidal in vitro activity against a wide variety of micro-organisms, including many clinically relevant bacteria (Table 1). MIC values for MPE indicated broad-spectrum and potent activity against a wide diversity of Gram-positive and Gram-negative bacteria. With a mean MIC of $1.2 \mu \mathrm{g} \mathrm{ml}^{-1}$ (based on the $\mathrm{MIC}_{50}$ values of the strains tested), the compound was bacteriostatic against every organism tested. It potently inhibited the growth of several important human pathogens, including Listeria monocytogenes, Pseudomonas aeruginosa and Sta. aureus, as well as bacteria known to resist the action of many AMPs, such as Enterococcus faecalis and Salmonella typhimurium (Tamayo et al., 2004). Potent activity was also shown against the aggressive pathogens B. anthracis and Francisella tularensis.

Based on the assumption that $\mathrm{mPE}$ reproduces the biochemical activity of AMPs, and is thus membrane-active, a major criterion for evaluation is its membrane selectivity. Haemolytic assays confirmed the selectivity of mPE for bacterial cells over human $\mathrm{RBCs}$ with an $\mathrm{HC}_{50}$ value of $75 \mu \mathrm{g} \mathrm{ml}^{-1}$. The ratio of $\mathrm{HC}_{50}$ to $\mathrm{MIC}_{50}$ is designated as a measure of membrane selectivity, and it was found to range from a low of 31 for some Gram-negative capsule-forming strains, to a high of 179-188 for several Gram-negative and Gram-positive strains (Table 1). It should be noted that haemolytic activity is a relatively crude measure of mammalian cytotoxicity and does not predict in vivo cytotoxicity. At the same time, the haemolysis assays technically only measure haemoglobin release caused by erythrocyte permeabilization, and thus the potential to injure, but not rupture mammalian cells was determined (Yeaman et al., 2002). Direct microscopic observation showed complete cell disintegration, supporting RBC lysis.

The MBC (reduction $\geqslant 3$ times $\log _{10}$ c.f.u.) for $\mathrm{mPE}$ against E. coli D31 was found to be $1.6 \mu \mathrm{g} \mathrm{ml}^{-1}$, confirming the bactericidal activity of mPE. This MBC value is twice the MIC value for this strain, which is a common characteristic of natural AMPs. A similar close relationship between MBC and MIC values was also found for the Grampositive B. subtilis ATCC 8037, for which MBC and MIC values were $3 \cdot 4$ and $1 \cdot 2 \mu \mathrm{g} \mathrm{ml}^{-1}$, respectively. For comparison, polymyxin $B$, a natural bacterium-derived polycationic amphiphilic AMP, was studied for selected strains, as a control antibiotic, and the results corroborated those reported in the literature (Table 1). This type of antimicrobial peptide is known to attack mostly Gram-negative bacteria and only a few Gram-positive bacteria (Dixon \& Chopra, 1986; Hancock \& Chapple, 1999).

Potent antibacterial activity was exhibited by $\mathrm{mPE}$ at MIC values comparable to natural AMPs, but these results were achieved in vitro. Therefore, we challenged the specificity of mPE for bacterial targets, with parallel competition between prokaryotic and eukaryotic cell membranes. The activity of mPE might decrease if it becomes unavailable due to the presence of excess mammalian cell membranes, or other molecules present in whole blood (Yeaman et al., 2002). With this in mind, we examined the potential for membrane competition by comparing pre-incubation versus co-incubation for combinations of drug, bacterial target cells and fresh human blood (Fig. 2). These experiments demonstrated that the efficacy of MPE was retained regardless of the presence of human blood. When mPE was preincubated with whole blood, the ex vivo bacteriostatic activity remained unchanged. All three pre-incubation and co-incubation variations in bacterial to eukaryotic cell ratios resulted in over $90 \%$ reduction of bacterial cell

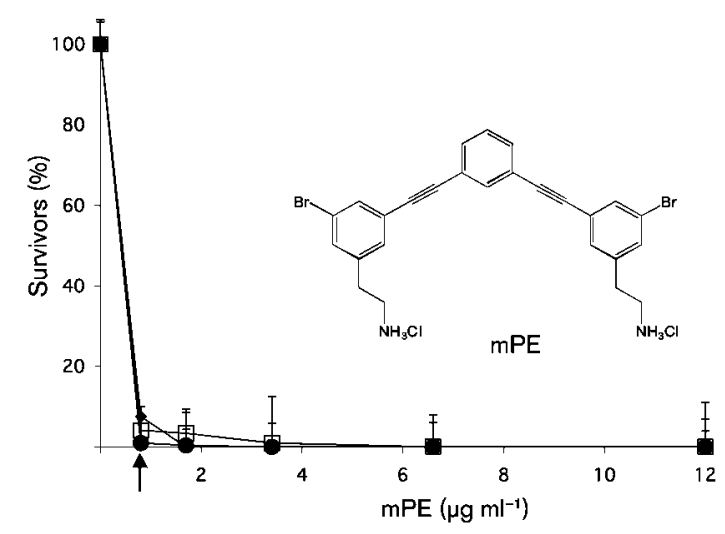

Fig. 2. Pre-incubation with human whole blood resulted in no loss of bactericidal action in subsequent mPE activity against E. coli C1S. This test served to determine whether competitive adherence to eukaryotic cell membranes reduces the amount of $\mathrm{mPE}$ available for bacteriostatic activity. The arrow indicates the MIC. The chemical line drawing shows the structure of $\mathrm{mPE}$. Similar results were obtained with B. subtilis ATCC 8037 (data not shown). Co-incubation of whole blood, bacterial cells and $\mathrm{mPE} ; \square$, pre-incubation of blood and mPE prior to the addition of bacteria; $\boldsymbol{O}$, pre-incubation of blood and bacteria prior to the addition of $\mathrm{mPE}$. The values are means $\pm \mathrm{SD}$. 
growth at the respective MIC values $\left(0 \cdot 8 \mu \mathrm{g} \mathrm{ml}^{-1}\right.$ for E. coli C1S and $1.6 \mu \mathrm{g} \mathrm{ml}^{-1}$ for B. subtilis) for the two bacterial strains assayed.

Pre-incubation of mPE with fresh whole blood did not affect the dose available for bacteriostatic activity, confirming the results from the haemolysis assays. However, the ability of $\mathrm{mPE}$ to interact with biological membranes remained an open question. As the killing mechanism for most biotic AMPs appears to be the permeabilization of the cytoplasmic membrane (Toke, 2005), we challenged living cells of the Gram-positive Sta. aureus in a cytoplasmic membrane permeabilization experiment. The release of a fluorescent dye due to the presence of $\mathrm{MPE}$ was monitored over time (Fig. 3). The membrane-potential-sensitive cyanine dye diSC3-5 distributes between cells and the culture medium depending on the cytoplasmic membrane potential gradient (Wu et al., 1999). Addition of mPE led to an increase in fluorescence, consistent with the release of dye due to the dissipating membrane potential as mPE disrupts the cell membrane. The shape of the curves indicates both the dependence on concentration, as well as on time. Even at low concentrations $\left(0 \cdot 4 \mu \mathrm{g} \mathrm{ml}^{-1}\right.$, one-quarter of the $\mathrm{MIC}_{90}$, supplementary Table S1, available at http://mic.sgmjournals. org) dye release was detected, although this was only $10 \%$. The kinetics of dye leakage was fast as MPE was first introduced to the cells, until free $\mathrm{mPE}$ in solution was decreased, which attenuated dye release. The highest concentration tested, $3 \cdot 2 \mu \mathrm{g} \mathrm{ml}^{-1}$, which was twice the $\mathrm{MIC}_{90}$, showed almost complete dye release. Thus, $\mathrm{mPE}$ was able to initiate membrane depolarization at only one-quarter of the $\mathrm{MIC}_{90}$ value; this is remarkable as some AMPs do not depolarize

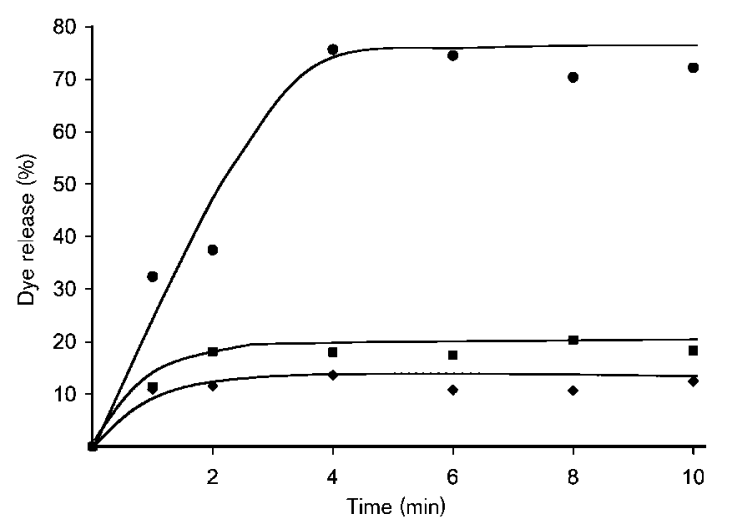

Fig. 3. Measurement of cytoplasmic membrane permeabilization using $3.2(\boldsymbol{0}), 0.8(\boldsymbol{\square})$ or $0.4(\boldsymbol{)}) \mu \mathrm{g}$ of the membranepotential-sensitive cyanine dye diSC $3-5 \mathrm{ml}^{-1}$ and Sta. aureus. Dye release was dose-dependent, with a significant percentage of dye released at 2.5 times the $\mathrm{MIC}_{90}(>70 \%)$, compared to typical AMPs which usually require four to ten times the $\mathrm{MIC}_{90}$. The results represent the mean of three independent experiments, with less than $10 \%$ SD. Similar results were achieved with $E$. coli D31 (data not shown). the membrane until they reach concentrations as high as four- to tenfold the $\mathrm{MIC}_{90}$.

Time-kill experiments were executed to determine bactericidal kinetics for $\mathrm{mPE}$, and they indicated that short exposure times were sufficient for killing over $50 \%$ within $10 \mathrm{~min}$ (Fig. 4). The strains used for these experiments were selected based on their similar levels of susceptibility to $\mathrm{mPE}$. A concentration-dependent susceptibility was demonstrated; the MIC rapidly reduced the number of surviving B. subtilis cells over the first $30 \mathrm{~min}$ (similar results for E. coli, data not shown), while a concentration of twice the MIC reduced the number of surviving cells to one-quarter of the original number. The rapid reduction in viable cell counts is a characteristic feature of membrane-permeating agents (Toke, 2005), consistent with the membrane-permeabilization experiments reported above. However, using plate counts for survival does not distinguish between adsorption of $\mathrm{mPE}$ to cell surfaces, which prevents colony formation, and immediate killing by $\mathrm{mPE}$. The latter was demonstrated by microscopic observation showing that most cells had lost their motility, which suggested loss of membrane potential within the first $30 \mathrm{~min}$ of exposure to $\mathrm{mPE}$.

It appears that $\mathrm{mPE}$ is not only a structural mimic of the host defence peptides, but also a functional mimic. mPE functions as a membrane-seeking amphiphilic molecule that binds to, and disrupts, microbial membranes. It has broadspectrum activity that strongly resembles that of many AMPs, and this suggests that a specific molecular inhibition or receptor-binding scenario is less likely. Kinetic studies further supported a fast-acting killing mechanism, typical of membrane-active AMPs. Therefore, it appears that $\mathrm{mPE}$

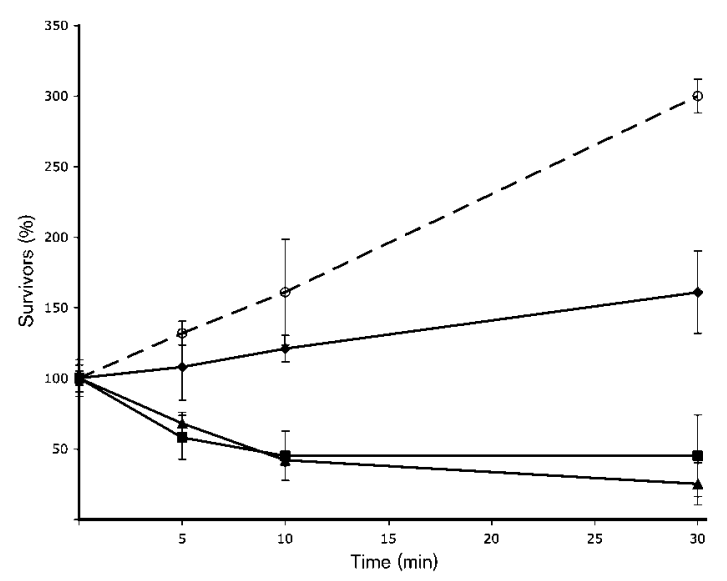

Fig. 4. Killing kinetics of selected bacterial strains by mPE. The quick-acting nature of this antimicrobial compound is indicated by the marked decrease in the number of survivors (in log units) of $B$. subtilis ATCC 8037 within the first 10 min. Each point represents the mean of four independent experiments and error bars represent SD. Similar results were achieved with $E$. coli C1S (data not shown). $\bigcirc$, Control; $\diamond, 0.5 \mathrm{MIC} ; \boldsymbol{\square}, \mathrm{MIC} ; \boldsymbol{\Delta}$, 2 MIC. 
embodies many of the attractive features of AMPs, but is achiral, non-proteolytic and potent. This report suggests that significant structural diversity can lead to the production of potent and selective antibacterial agents that offer a novel approach in the battle against bacterial resistance.

Further research into molecules that mimic biotic AMPs will enhance our insight into the essential design elements needed to reproduce biological activity and might enable the development of novel antibiotics.

\section{ACKNOWLEDGEMENTS}

We thank A. Papa for technical support with some of the biological experiments, and M. Riley for helpful edits of the manuscript. This work was supported by grants from the National Science Foundation, PolyMedix, the Presidential Early Career Award for Scientists and Engineers, and awards for Army Research Office Young Investigator and Office of Naval Research Young Investigator.

\section{REFERENCES}

Andreu, D. \& Rivas, L. (1998). Animal antimicrobial peptides: an overview. Biopolymers 47, 415-433.

Arnt, L. \& Tew, G. N. (2002). New poly(phenyleneethynylene)s with cationic, facially amphiphilic structures. J Am Chem Soc 124, 7664-7665.

Arnt, L., Nüsslein, K. \& Tew, G. N. (2004). Nonhemolytic abiogenic polymers as antimicrobial peptide mimics. J Polymer Sci A Polymer Chem 42, 3860-3864.

Barry, A. L. (1976). The Antimicrobic Susceptibility Test: Principles and Practice. Philadelphia, PA: Lea \& Feliger.

Broekaert, W. E. F., Cammue, B. P. A., De Bolle, M. F. C., Thevissen, K., De Samblanx, G. W. \& Osborn, R. W. (1997). Antimicrobial peptides from plants. Crit Rev Plant Sci 16, 297-323.

Bucki, R., Pastore, J. J., Randhawa, P., Vegners, R., Weiner, D. J. \& Janmey, P. A. (2004). Antibacterial activities of rhodamine B-conjugated gelsolin-derived peptides compared to those of the antimicrobial peptides cathelicidin LL37, magainin II, and melittin. Antimicrob Agents Chemother 48, 1526-1533.

Bulet, P., Hetru, C., Dimarcq, J. L. \& Hoffmann, D. (1999). Antimicrobial peptides in insects; structure and function. Dev Comp Immunol 23, 329-344.

Dixon, R. A. \& Chopra, I. (1986). Polymyxin B and polymyxin B nonapeptide alter cytoplasmic membrane permeability in Escherichia coli. J Antimicrob Chemother 18, 557-563.

Guerrero, E., Saugar, J. M., Matsuzaki, K. \& Rivas, L. (2004). Role of positional hydrophobicity in the leishmanicidal activity of magainin 2. Antimicrob Agents Chemother 48, 2980-2986.

Hancock, R. E. W. \& Chapple, D. S. (1999). Peptide antibiotics. Antimicrob Agents Chemother 42, 1317-1323.

Hancock, R. E. W. \& Diamond, G. (2000). The role of cationic antimicrobial peptides in innate host defences. Trends Microbiol 8, 402-410.

Huang, H. W. (2000). Action of antimicrobial peptides: two-state model. Biochemistry 39, 8347-8352.

Kohli, R. M., Walsh, C. T. \& Burkart, M. D. (2002). Biomimetic synthesis and optimization of cyclic peptide antibiotics. Nature 418, $658-661$.
Li, C., Budge, L. P., Driscoll, C. D., Willardson, B. M., Allman, G. W. \& Savage, P. B. (1999). Incremental conversion of outer-membrane permeabilizers into potent antibiotics for Gram-negative bacteria. J Am Chem Soc 121, 931-940.

Liu, D., Choi, S., Chen, B., Doerksen, R. J., Clements, D. J., Winkler, J. D., Klein, M. L. \& DeGrado, W. F. (2004). Nontoxic membraneactive antimicrobial arylamide oligomers. Angew Chem Int Ed Engl 43, 1158-1162.

Monner, A., Jonsson, S. \& Boman, H. G. (1971). Ampicillin-resistant mutanys of Escherichia coli K-12 with lipopolysaccharide. J Bacteriol 107, 420-432.

National Committee for Clinical Laboratory Standards (1999). Methods for Determining Bactericidal Activity of Antimicrobial Agents; Approved Guideline. Document M26-A. Wayne, PA: National Committee for Clinical Laboratory Standards.

National Committee for Clinical Laboratory Standards (2003). Methods for Dilution Antimicrobial Susceptibility Tests for Bacteria That Grow Aerobically; Approved Standard, 6th edn. Document M7-A6. Wayne, PA: National Committee for Clinical Laboratory Standards.

Porter, E. A., Wang, X., Lee, H. S., Weisblum, B. \& Gellman, S. H. (2000). Non-haemolytic beta-amino acid oligomers. Nature 404, 565.

Shai, Y. \& Oren, Z. (2001). From 'carpet' mechanism to de-novo designed diastereomeric cell-selective antimicrobial peptides. Peptides 22, 1629-1641.

Steinberg, D. A., Hurst, M. A., Fujii, C. A., Kung, A. H., Ho, J. F., Cheng, F. C., Loury, D. J. \& Fiddes, J. C. (1997). Protegrin-1: a broad-spectrum, rapidly microbicidal peptide with in vivo activity. Antimicrob Agents Chemother 41, 1738-1742.

Strøm, M. B., Haug, B. E., Skar, M. L., Stensen, W., Stiberg, T. \& Svendsen, J. S. (2003). The pharmacophore of short cationic antibacterial peptides. J Med Chem 46, 1567-1570.

Tamayo, R., Portillo, A. C. \& Gunn, J. S. (2004). Mechanisms of bacterial resistance to antimicrobial peptides. In Mammalian Host Defense Peptides, pp. 323-348. Edited by D. A. Devine \& R. E. W. Hancock. Cambridge: Cambridge University Press.

Tew, G. N., Liu, D., Chen, B., Doerksen, R. J., Kaplan, J., Carroll, P. J., Klein, M. L. \& DeGrado, W. F. (2002). De novo design of biomimetic antimicrobial polymers. Proc Natl Acad Sci U S A 99, 5110-5114.

Toke, O. (2005). Antimicrobial peptides: new candidates in the fight against bacterial infections. Biopolymers 80, 717-735.

Walsh, C. (2003). Antibiotics: Actions, Origins, Resistance. Washington, DC: American Society for Microbiology.

Wu, M., Maier, E., Benz, R. \& Hancock, R. E. W. (1999). Mechanism of interaction of different classes of cationic antimicrobial peptides with planar bilayers and with the cytoplasmic membrane of Escherichia coli. Biochemistry 38, 7235-7242.

Yeaman, M. R., Gank, K. D., Bayer, A. S. \& Brass, E. P. (2002) Synthetic peptides that exert antimicrobial activities in whole blood and blood-derived matrices. Antimicrob Agents Chemother 46, 3883-3891.

Yount, N. Y. \& Yeaman, M. R. (2005). Multidimensional signatures in antimicrobial peptides. Proc Natl Acad Sci U S A 101, 7363-7368.

Zasloff, M. (2002). Antimicrobial peptides of multicellular organisms. Nature 415, 389.

Zhang, L., Rozek, A. \& Hancock, R. E. (2001). Interaction of cationic antimicrobial peptides with model membranes. J Biol Chem 276, 35714-35722. 